\title{
Adoption of agile software methodology among the SMEs developing an IoT applications
}

\begin{abstract}
Agile software methodology framework has been used frequently in the software development industry especially among the small medium (SME) companies. In this paper, we conducted a case study among the four selected SME companies that have been developing the Internet of Things application (IoT) as their business core. The results found that all the companies under study are using extreme programming (XP), Dynamic System Development Methodology (DSDM), Feature Driven Development (FDD) and Lean as chosen development methodology. However, the most used agile methodology framework is the Scrum techniques. The study shows that companies applied Agile SDM. This is because, the Agile SDM help the software developer teams to organize their task efficaciously, and able to make frequent delivery to their stakeholders and users.
\end{abstract}

Keyword: Agile software methodology; Internet of things; Small medium enterprise 